\title{
Expression of pEGFR and pAKT as response-predictive biomarkers for RAS wild-type patients to anti-EGFR monoclonal antibodies in metastatic colorectal cancers
}

\author{
A Harlé ${ }^{* 1,2,3}$, J Salleron ${ }^{4}$, G Perkins ${ }^{5}$, C Pilati ${ }^{5}, \mathrm{H} \mathrm{Blons}^{5}$, P Laurent-Puig ${ }^{5}$ and J L Merlin ${ }^{1,2,3}$ \\ ${ }^{1}$ Université de Lorraine, Faculté de Pharmacie, 54001 Nancy, France; ${ }^{2}$ CNRS UMR 7039 CRAN, 54506 Vandoeuvre les Nancy, \\ France; ${ }^{3}$ Institut de Cancérologie de Lorraine, Service de Biopathologie, 54519 Vandoeuvre les Nancy, France; ${ }^{4}$ nstitut de \\ Cancérologie de Lorraine, Cellule Data Biostatistique, 54519 Vandoeuvre les Nancy, France and Institut National de la Santé et \\ de la Recherche Médicale (INSERM), Unité Mixte de Recherche (UMR)-S1147, Personalized Medicine, Pharmacogenomics, \\ Therapeutic Optimization, Université Paris Descartes, 45 rue des Saints Pères, 75006 Paris, France
}

Background: RAS wild-type (RAS $/ / t)$ tumours have been associated with better outcomes in patients with metastatic colorectal cancer (mCRC) treated with anti-EGFR monoclonal antibodies (mAb). We investigated the expression of EGFR downstream proteins under their active phosphorylated forms as potential markers in response to these patients.

Methods: One-hundred tumour samples were collected from patients with mCRC refractory to FOLFOX and/or FOLFIRI and treated by a combination of chemotherapy with anti-EGFR mAb. The outcomes were measured on response evaluation criteria in solid tumour (RECIST), progression-free survival (PFS) and overall survival (OS). All samples were assessed for RAS and BRAF mutations, and the key phosphorylated proteins of EGFR downstream signalling were quantitatively analysed using the BioPlex Protein array.

Results: Among the $60 \mathrm{RAS}_{w / t}$ patients, $45.0 \%$ achieved a complete or partial response when treated with anti-EGFR mAb. Expression of pAKT, pERK1/2 and pMEK1 was significantly lower in RAS $w / t$ patients $(P=0.0246 ; P=0.004 ; P=0.0110$, respectively). The response rate was significantly higher for RAS $_{w / t}$ patients who express $p E G F R$ and pAKT $(P=0.0258 ; P=0.0277$, respectively).

Conclusions: Overexpression of pEGFR and pAKT may predict the response rate in RAS $\mathrm{s}_{\mathrm{w} / \mathrm{t}}$ patients treated with anti-EGFR mAb. On the basis of our results, we hypothesise that the association of anti-EGFR mAb and anti-AKT therapies could be of interest.

Colorectal cancer is the third most common cancer worldwide with more than one million patients diagnosed each year, among $50 \%$ of whom will develop metastatic disease (Jemal et al, 2011; Tougeron et al, 2013). Recent efforts to improve the treatment of metastatic colorectal cancer (mCRC) have led to the development of monoclonal antibodies (mAbs) such as cetuximab and panitumumab that inhibit the activation of the epidermal growth factor receptor (EGFR) and its downstream pathways (namely RAS/RAF/
MAPK and PI3K/AKT/mTOR) that promote cell growth, proliferation, inhibition of apoptosis, invasion and metastasis. Evidence has first showed that patients with codon 12 or 13 KRAS-mutant tumours receive little or no benefit from anti-EGFR therapies as single agents or combined with chemotherapy (Di Fiore et al, 2007; Khambata-Ford et al, 2007; De Roock et al, 2008; Lievre et al, 2008). More recent studies revealed that the presence of mutations on exons 2, 3 and 4 of KRAS or NRAS were also predictive of 
resistance to anti-EGFR therapies (Douillard et al, 2013; Sorich et al, 2014). In other words, cetuximab or panitumumab shows benefits only to ' $R A S$ wild-type' patients, that is, patients with tumours that are not bearing mutations on exons 2, 3 and 4 of KRAS and NRAS. These findings led the European Medicine Agency to the use of cetuximab and panitumumab for patients with RAS wild-type tumours.

However, from studies including RAS wild-type patients, the response rates to cetuximab or panitumumab therapy ranged from only 40 to $60 \%$ (Linardou et al, 2008), which results in a large fraction of patients being without any known causes for treatment failure. The presence of alterations in other genes such as PIK3CA or $B R A F$ in the EGFR-dependent signalling pathways (LaurentPuig et al, 2009; Custodio and Feliu, 2013; Douillard et al, 2013) is responsible for some of the non-responding cases. Moreover, overexpression or alterations on proteins such as PTEN, PI3K and AKT, involved in the RAS/RAF/MAPK or PI3K/AKT/mTOR signalling pathways, can have a significant impact on cell proliferation or apoptosis. Absence or overexpression of proteins under their phosphorylated forms may be of interest to predict response to anti-EGFR $\mathrm{mAb}$. Ligand fixation of the EGF receptor activates the pathway. The fixation of ligand on the receptor activates the kinase activity that is responsible for the activation of downstream proteins by phosphorylation. The study of the expression of the downstream proteins under their phosphorylated forms is important to understand mechanisms of resistance to anticancer drugs and more precisely in our study of anti-EGFR drugs. In a previous study, we showed that the expression level of EGFR downstream signalling phosphoproteins (pMEK1 and pP70S6K) could predict longer progression-free survival (PFS) and overall survival (OS) in KRAS exon 2 wild-type mCRC using multivariate analysis (Perkins et al, 2010).

In this paper, we describe the impact of RAS mutations (that is, KRAS and NRAS exon 2, 3 and 4 mutations) and of the expression of proteins involved in RAS/RAF/MAPK and PI3K/AKT/mTOR pathways in their active phosphorylated forms on the response to anti-EGFR mAbs in RAS wild-type patients with an advanced colorectal cancer. The 42 patient population described in our previous study (Perkins et al, 2010) has been extended to 100 patients, and the research of mutations has been also extended from KRAS exon 2 to RAS (KRAS, NRAS) exons 2, 3 and 4.

\section{PATIENTS AND METHODS}

Patients. We analysed total protein extracts prepared from 100 frozen tumour samples from patients with mCRC treated by a combination of chemotherapy with anti-EGFR therapy, from the collection that has been already described (Lievre et al, 2008; Laurent-Puig et al, 2009). Characteristics of the patients are shown in Table 1. All patients were refractory to FOLFOX and/or FOLFIRI regimen and were treated with anti-EGFR antibodies. In summary, $95 \%$ of the patients were treated by a combination of anti-EGFR and irinotecan, $2 \%$ were treated by a monotherapy using cetuximab or panitumumab, $1 \%$ were treated by a combination of anti-EGFR with a chemotherapy associating 5 -fluorouracil and oxaliplatin and 1\% were treated by 5-fluorouracil. The outcomes were measured on RECIST, PFS and OS. Evaluation was measured every 2 to 3 months according to French standard of care. Patients with complete and partial responses were considered as responders and patients with stable disease or progression as non-responders. Tumours were collected at the time of surgery. All samples were available either as frozen samples or as formalinfixed paraffin-embedded tissues. This study has been approved by the Ile-de-France ethical committee number 2 (ID-RCBAO1058-47/2008-135).
Table 1. Characteristics of patients analysed for EGFR pathway protein using the Bioplex protein assay

\begin{tabular}{|c|c|}
\hline Median age (years; range) & $61(22-80)$ \\
\hline \multicolumn{2}{|l|}{ Gender } \\
\hline Male & 58 \\
\hline Female & 41 \\
\hline NA & 1 \\
\hline \multicolumn{2}{|c|}{ Number of chemotherapy line used before anti-EGFR } \\
\hline 0 & $0 \%$ \\
\hline 1 & $5 \%$ \\
\hline 2 & $46 \%$ \\
\hline 3 & $36 \%$ \\
\hline 4 & $8 \%$ \\
\hline 5 & $3 \%$ \\
\hline 6 & $2 \%$ \\
\hline \multicolumn{2}{|l|}{ Death } \\
\hline Yes & $83 \%$ \\
\hline No & $17 \%$ \\
\hline Median OS (month-range) & $10.0(0.1-48.1)$ \\
\hline Median PFS (month-range) & $4.1(0-20.0)$ \\
\hline \multicolumn{2}{|l|}{ Response } \\
\hline Complete response & $2 \%$ \\
\hline Partial response & $26 \%$ \\
\hline Stable disease & $34 \%$ \\
\hline Progressive disease & $37 \%$ \\
\hline NA & $1 \%$ \\
\hline \multicolumn{2}{|l|}{ WHO } \\
\hline 0 & $28 \%$ \\
\hline 1 & $48 \%$ \\
\hline 2 & $11 \%$ \\
\hline 3 & $1 \%$ \\
\hline NA & $12 \%$ \\
\hline \multicolumn{2}{|l|}{ Mutation } \\
\hline KRAS & $36 \%$ \\
\hline NRAS & $4 \%$ \\
\hline BRAF & $2 \%$ \\
\hline
\end{tabular}

Protein extraction. Whole-cell protein extraction was performed from 5-mm frozen tumour tissues using the Kit RIPA lysis Buffer 1X (Tebubio, Le Perray en Yvelines, France) prepared with inhibitors (PMSF, protease inhibitor cocktail and sodium orthonavate; Dutscher, Brumath, France) according to the manufacturer's recommendations.

Phosphoprotein analysis. The expression of phosphorylatedEGFR $\left(\operatorname{pEGFR}_{(\mathrm{Tyr})}\right)$ and the key phosphorylated proteins of EGFR downstream signalling pathway such as $\mathrm{pAKT}_{(\mathrm{Ser473)}}$, pERK1-2 (Thr202/Tyr204, Thr185/Tyr187), pGSK3 (Ser21/Ser9), pIGF1R (Tyr1131), $\mathrm{pMEK}_{(\text {Ser217/Ser221), }}$ PP70S6K (Thr421/Ser424) $_{\text {and pP90RSK }}$ (Thr359/Ser363) were quantitatively analysed in freshly frozen samples using BioPlex Protein assay (BPA; Bio-Rad, Marnes-la-coquette, France) as previously described and validated (Chergui et al, 2009). This technique is on the basis of multiplex sandwich bead immunoassays. Protein extracts were transferred into 96-well dishes and diluted with buffered solution. Fluorescent capture beads coupled to antibodies directed against the phosphoproteins $\mathrm{pEGFR}_{(\mathrm{Tyr})}$,

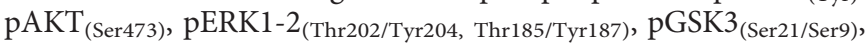
pIGF1R $_{(\text {Tyr1131), }}$ pMEK1 $1_{(\text {Ser217/Ser221), }}$ pP70S6K (Thr421/Ser424) $_{\text {and }}$ pP90RSK $_{(\text {Thr359/Ser363) }}$ were mixed and added into each well and incubated overnight. Following incubation, the plates were washed and incubated with biotinylated antibodies fixing each target protein. Streptavidin-phycoerythrin solution was then added. The analysis consisted of a double laser fluorescence detection allowing 
simultaneous identification of the target protein through the red fluorescence emission signal of the bead and quantification of the target protein through the fluorescence intensity of phycoerythrin. Results were recorded as the mean fluorescence intensities and compared with negative controls. Positive controls consisting of standard protein extracts from cell lines were added to each series. All results were normalised through the different batches of analyses by the same mutated tumour sample. The expression level of each phosphoprotein was recorded as fluorescence arbitrary unit. BPA assay requires $15-20 \mathrm{mg}$ of tissue containing more than $50 \%$ of tumour material or equivalent amount of protein extract (that is, $25 \mathrm{mg}$ total protein per assay in triplicate). All samples were assessed in triplicate to ensure reproducibility of the data.

Determination of KRAS, NRAS and BRAF mutations. KRAS exon 2 and 3 and BRAF exon 15 mutation statuses were assessed by allelic discrimination using TaqMan qPCR probes as previously described (Lievre et al, 2008; Laurent-Puig et al, 2009). KRAS exon 4 and NRAS exon 2, 3 and 4 mutation statuses were assessed using Sanger sequencing and next-generation sequencing. Patients with wild-type tumours for exons 2, 3 and 4 of KRAS and NRAS were considered as «RAS wild-type».

Statistical analysis. Statistical analysis was performed using the SAS software (SAS Institute, Cary, NC, USA 25513; version 9.2). A $P$-value $<0.05$ was considered as statistically significant.

Quantitative variables were described by the mean, median and interquartile range, and qualitative variables by frequency and percentage. The normality of the distribution of the expression of each phosphoprotein was assessed with the Shaprio-Wilk test.

Overall survival and PFS were described using the KaplanMeier method and compared between RAS mutation status with bivariate Cox proportional hazard model. Comparisons of each phosphoprotein according to the RAS mutation status were performed by a Mann-Whitney $U$-test.

In the subgroup of RAS wild-type patients, the discriminant power of each phosphoprotein to predict the response rate was estimated with the area under the receiver operating characteristic (AUC) and their 95\% confidence intervals. An AUC equal to 0.5 corresponds to no discrimination; an AUC between 0.5 and 0.7 means a low discriminant power; an AUC between 0.7 and 0.8 corresponds to an acceptable discrimination and above 0.8 to an excellent discrimination. Each phosphoprotein was then dichotomised according to the best cutoff maximising the sensitivity and the specificity. These thresholds were computed owing to the Youden Index.

The percentage of response rate was calculated for each level of the new binary variables and compared with a $\chi^{2}$-test or a Fisher Exact test. The odds ratio and their $95 \%$ confidence interval were computed with a bivariate logistic regression.

The phosphoproteins with a $P$-value less than 0.2 in bivariate analysis were introduced in a multivariate logistic regression with backward selection (Harrell et al, 1996). The stability of the selected model was investigated using the bootstrap-resampling method (Sauerbrei and Schumacher, 1992). The discriminant power of the final model was estimated using the AUC with $95 \%$ CI. We addressed the optimism bias using a bootstrap-resampling method. The stability of the score was estimated by crossvalidation (Altman and Royston, 2000).

\section{RESULTS}

Among the 100 tumour samples, 40 were found with a $R A S$ mutation (36\% with KRAS mutation and $4 \%$ with NRAS mutation) and $60 \%$ were $R A S$ wild type. Among the RAS wild-type patients, $45.0 \%$ achieved a complete or partial response, and $55.0 \%$ had a stable disease or progression $(P<0.001)$ when treated with anti-
EGFR. Patients with a RAS mutation had significant lower PFS $(\mathrm{HR}=3.04 \quad(1.91 ; 4.83))$ and $\mathrm{OS} \quad(\mathrm{HR}=2.49 \quad(1.56 ; 3.97))$. Progression-free survival and OS were significantly higher in $R A S$ wild-type patients (Figure 1). Expression levels of pAKT, pERK1/2 and pMEK1 were significantly lower in $R A S$ wild-type patients than in RAS-mutated patients $(P=0.0246 ; P=0.004$; $P=0.0110$, respectively), and no significant difference was observed between RAS wild-type and RAS-mutated tumours in the expression of pEGFR, pGSK3, pIGFR, pP70S6K and pP90SRK (Table 2).

In $R A S$ wild-type patients, the AUC of the expression of each phosphoprotein according to the response rate were under 0.80 . After dichotomising the expression of each phosphoprotein with the best threshold to maximise the sensitivity and the specificity, the response rate was significantly higher for tumours that express pEGFR and pAKT above the calculated threshold $(P=0.0258$ and $P=0.0277$, respectively). No significant relation was found between the response rate and the level of expression of the other phosphoproteins (Table 3a).

These two phosphoproteins remained statistically significant in multivariate analysis to predict response after bootstrap validation (Table 3b). The AUC of the final model was 0.673 (95\% CI (0.540; 0.805)). After correction for the optimism bias, the AUC was 0.654. The cross-validation covariate was associated with a (beta) value of 1.08 close to 1 .

No statistically significant difference was found between expression of phosphoproteins and PFS or OS in RAS wild-type tumour-bearing patients (data not shown).

\section{DISCUSSION}

The development of molecular biology and knowledge about signalling pathways in cancer have been a real opportunity to
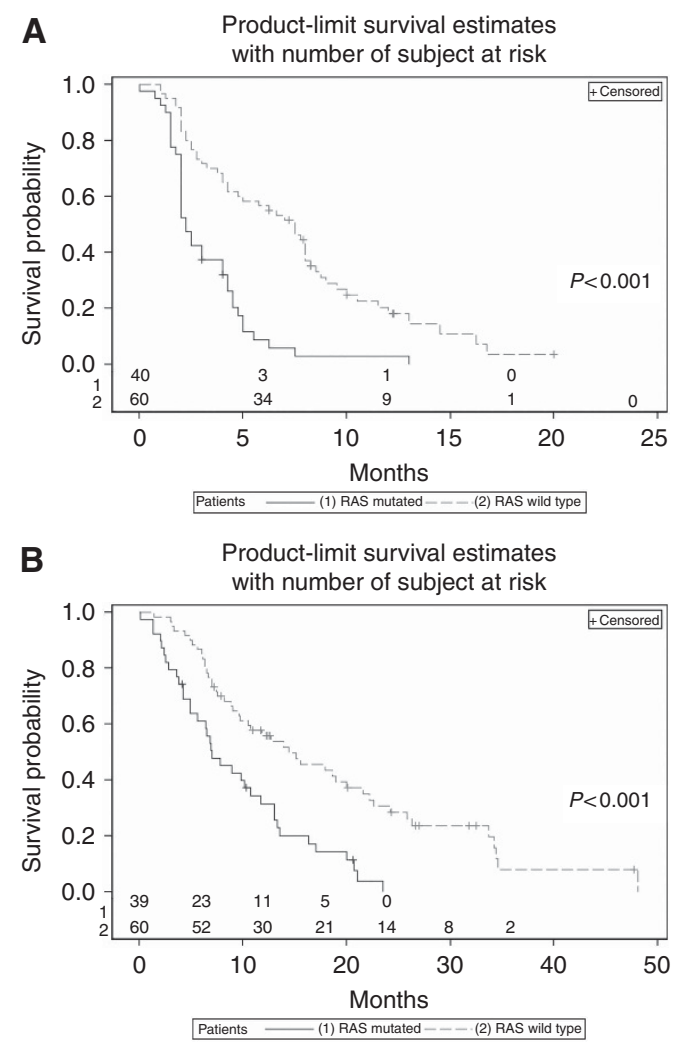

Figure 1. Kaplan-Meier's curve of RAS wild-type and RAS-mutated patients for PFS (A) and OS (B). 
Table 2. Expression of phosphoproteins in all samples, RAS-mutated samples and RAS wild-type samples

\begin{tabular}{|l|c|c|c|c|}
\hline & All* & RAS mutated* $^{*}$ & RAS wild type* & $\boldsymbol{P}$ \\
\hline pAKT & $104.01 ; 98.5(86.04 ; 124.55)$ & $110.79 ; 109.46(93.31 ; 126.27)$ & $99.49 ; 92.83(82.10 ; 122.07)$ & 0.0246 \\
\hline pEGFR & $139.35 ; 109.39(86.69 ; 141.04)$ & $174.69 ; 105.38(88.58 ; 146.54)$ & $115.80 ; 110.11(85.16 ; 139.13)$ & 0.9355 \\
\hline pERK1/2 & $245.73 ; 138.98(101.59 ; 263.85)$ & $350.22 ; 178.23(137.87 ; 395.01)$ & $176.07 ; 113.83(92.04 ; 169.58)$ & 0.0004 \\
\hline pGSK3 & $133.03 ; 101.05(66.38 ; 183.82)$ & $135.62 ; 97.79(66.38 ; 168.41)$ & $131.30 ; 105.88(65.32 ; 184.71)$ & 0.7676 \\
\hline pIGFR & $83.65 ; 74.83(64.29 ; 96.68)$ & $83.52 ; 70.81(63.89 ; 91.62)$ & $83.74 ; 77.13(64.70 ; 101.09)$ & 0.4024 \\
\hline pMEK1 & $272.19 ; 131.82(80.42 ; 280.74)$ & $411.25 ; 209.52(87.89 ; 402.14)$ & $179.48 ; 104.09(77.70 ; 201.28)$ & 0.0110 \\
\hline pP7OS6K & $123.31 ; 112.49(89.14 ; 135.21)$ & $131.39 ; 124.47(93.58 ; 136.83)$ & $117.93 ; 105.24(85.00 ; 135.21)$ & 0.1690 \\
\hline pP9OSRK & $74.37 ; 75.61(49.71 ; 95.38)$ & $81.03 ; 80.27(48.73 ; 101.78)$ & $69.93 ; 71.78(50.11 ; 88.26)$ & 0.1303 \\
\hline Expression of pAKT, pERK1/2 and pMEK1 is significantly lower in RAS wild-type patients. ${ }^{*}$ Mean; median (lower quartile; upper quartile). \\
\hline
\end{tabular}

Table 3. Expression of phoshoproteins and response rate

\begin{tabular}{|c|c|c|c|c|c|}
\hline prot & Aur and $050 /$ & Throcholda & CD PD & Duglug & OP and $050 / \mathrm{CI}$ \\
\hline PAKT & $0.588(0.436 ; 0.74)$ & $\begin{array}{l}<120 \\
\geqslant 120\end{array}$ & $\begin{array}{l}36.36 \%(16) \\
68.75 \%(11)\end{array}$ & 0.0258 & $\begin{array}{c}1 \\
3.85(1.13 ; 13.07)\end{array}$ \\
\hline pEGFR & $0.634(0.491 ; 0.776)$ & $\begin{array}{l}<100 \\
\geqslant 100\end{array}$ & $\begin{array}{l}25.00 \%(5) \\
55.00 \%(22)\end{array}$ & 0.0277 & $\begin{array}{c}1 \\
3.67(1.12 ; 12.03)\end{array}$ \\
\hline pERK1/2 & $0.497(0.348 ; 0.646)$ & $\begin{array}{l}<110 \\
\geqslant 110\end{array}$ & $\begin{array}{l}38.45 \%(10) \\
50.00 \%(17)\end{array}$ & 0.373 & $\begin{array}{c}1 \\
1.60(0.57 ; 4.51)\end{array}$ \\
\hline pGSK3 & $0.504(0.355 ; 0.653)$ & $\begin{array}{l}<130 \\
\geqslant 130\end{array}$ & $\begin{array}{l}38.24 \%(13) \\
53.85 \%(14)\end{array}$ & 0.228 & $\begin{array}{c}1 \\
1.88(0.67 ; 5.31)\end{array}$ \\
\hline PIGFR & $0.513(0.365 ; 0.662)$ & $\begin{array}{l}<60 \\
\geqslant 60\end{array}$ & $\begin{array}{l}33.33 \%(3) \\
47.06 \%(24)\end{array}$ & 0.445 & $\begin{array}{c}1 \\
1.78(0.40 ; 7.89)\end{array}$ \\
\hline pMEK1 & $0.497(0.348 ; 0.646)$ & $\begin{array}{l}<100 \\
\geqslant 100\end{array}$ & $\begin{array}{l}38.46 \%(10) \\
50.00 \%(17)\end{array}$ & 0.373 & $\begin{array}{c}1 \\
1.60(0.57 ; 4.51)\end{array}$ \\
\hline pP70S6K & $0.585(0.439 ; 0.731)$ & $\begin{array}{l}<105 \\
\geqslant 105\end{array}$ & $\begin{array}{l}36.67 \%(11) \\
53.33 \%(16)\end{array}$ & 0.194 & $\begin{array}{c}1 \\
1.97(0.70 ; 5.54)\end{array}$ \\
\hline pP90SRK & $0.577(0.43 ; 0.723)$ & $\begin{array}{l}<70 \\
\geqslant 70\end{array}$ & $\begin{array}{l}35.71 \%(10) \\
53.13 \%(17)\end{array}$ & 0.176 & $\begin{array}{c}1 \\
2.04(0.72 ; 5.77)\end{array}$ \\
\hline \multicolumn{6}{|l|}{ (b) } \\
\hline \multicolumn{6}{|c|}{ Multivariate } \\
\hline pProt & OR and $95 \% \mathrm{Cl}$ & & & & \\
\hline pAKT & $\begin{array}{c}1 \\
3.70(1.04 ; 13.18)\end{array}$ & & & & \\
\hline pEGFR & $\begin{array}{c}1 \\
3.53(1.03 ; 12.11)\end{array}$ & & & & \\
\hline \multicolumn{6}{|c|}{$\begin{array}{l}\text { Abbreviations: } A U C=\text { area under the receiver operating characteristic; } C l=\text { confidence interval; } C R=\text { complete response; } O R=\text { odds ratio; } P R=\text { partial response. (a) Patients with expression of } \\
\text { pAKT over } 120 \text { and pEGFR over } 100 \text { achieved significantly better response rate. (b) These two phosphoproteins remained statistically significant in multivariate analysis to predict response after } \\
\text { bootstrap validation. Statistically significant } p \text {-values are presented in bold. } \\
\text { a Optimal threshold according to the Youden index. }\end{array}$} \\
\hline
\end{tabular}

improve treatment for patients with mCRC. The history of RAS and the use of anti-EGFR therapies are characteristic of the importance of identifying response-predictive biomarkers and molecular testing. Unluckily, a large proportion of $R A S$ wild-type patients do not reach benefit from anti-EGFR-targeted therapies and it is important to explore new targets and identify patients who will benefit from targeted therapies. The selection of these patients is crucial to avoid unworthy toxicities or inefficient treatment, but also for economic issues.

In our study, the repartition of RAS mutation in the studied population is consistent with previously published data (Sorich et al, 2014). The observed response rate is also consistent with known data with few or no response in RAS-mutant tumour (Bokemeyer et al, 2012). Complete or partial responses were achieved in $\sim 45.0 \%$ of RAS wild-type tumour-bearing patients, which is higher than that described in previously published data for patients treated for second or further line with an association for anti-EGFR and FOLFIRI (Iwamoto et al, 2014). This difference can probably be related to the lower median age of our population and the better WHO status.

The level of expression of phosphoproteins in the RAS-mutated patients was found to be significantly higher than in RAS wild-type patients as we expected. The accumulation of RAS protein under its activated form causes the activation of RAF/RAS/MAPK and $\mathrm{PI} 3 \mathrm{~K} / \mathrm{AKT} / \mathrm{mTOR}$ signalling pathways, resulting in an overexpression of the downstream proteins involved in these pathways (Newbold, 1984).

In our study, the level of expression of phosphoproteins was measured with the BPA and not with immunohistochemistry. BPA is a validated method and is comparable to western blot analysis (Chergui et al, 2009). Most of the studies published in the literature are using western blot or immunohistochemistry, which are 
qualitative and semiquantitative assays, respectively. BPA is a quantitative assay and allows more precision in the measurement of the level of phosphorylated proteins. However, immunohistochemistry allows the determination of the expression according to the localisation of the target-that is, nucleus, cytoplasm, stroma and so on-whereas BPA is using the whole tumour and is unable to determine the localisation of the overexpression in the cell. This difference of technical approach may be responsible to the discrepancies we will discuss further in this paragraph.

Overexpression of pEGFR and pAKT was significantly associated with higher response rate in RAS wild-type patients; however, no statistically significant relation was found between the expression of phosphoproteins and PFS and OS. These date do not confirm our previously published data (Perkins et al, 2010). In the study published by Perkins et al (2010), PFS was related to a lower expression of pMEK and pP70S6K in wild-type KRAS exon 2 tumour-bearing patients. Among the 42 patients included in this study, only 23 were wild-type KRAS tumour-bearing. The lack of subjects in the wild-type KRAS class and the impact of KRAS exon 3, 4 and NRAS exon 2, 3 and 4 mutations may explain this difference with our present data. Moreover, although being in the same order as sample sizes in other papers investigating phosphorylated proteins as putative response-predictive biomarkers in mCRC (Scartozzi et al, 2012; Cejas. et al, 2012), the statistical power would have been better with a larger sample size and these results have to be confirmed in the future on a largest population.

In our paper, phosphoproteins have been extracted and analysed from primary tumours; however, some studies suggest that the correlation of the expression of EGFR and AKT between the primary and the metastasis does not appear in $20-40 \%$ of cases (Scartozzi et al, 2012; Cejas. et al, 2012). However, in these two papers $\mathrm{pEGFR}$ and $\mathrm{pMAPK}$ have been investigated using IHC considering weakly stained samples as negative. In our paper, phosphorylated protein expression was quantified in frozenspecimen protein extracts and considered as positive when exceeding $3 \times$ the background noise value, as validated in Chergui et al (2009). In addition, in these two papers, the analyses were performed in FFPE specimens, which does not warrant optimal preservation of phosphoproteins as the freezing procedure we used. According to these published data, it would be of interest to compare the expression of pEGFR and pAKT in primary and metastasis in a larger series of samples and to compare these data to response rate, PFS and OS.

The relation between the overexpression of pEGFR and response rate has already been described (Razis et al, 2014) and can be explained by the avidity of the tumour cell for its ligand: the more the cell is dependent on its ligand, the more EGFR will be expressed and the more anti-EGFR will be effective against tumour cells. Considering this ligand avidity, it is not surprising that a better response rate was achieved with anti-EGFR with $R A S$ wildtype tumours overexpressing pEGFR. More surprisingly, a significant relation has been found between higher response rate and overexpression of pAKT. It is known that activation of AKT is dependent on the activation of EGFR (Mirzoeva et al, 2009). It has also been described that expression of pAKT was associated with lower response rate and lower PFS (Scartozzi et al, 2012); however, the studied population was selected between 2007 and 2011, and no indication mentions whether the patients treated by anti-EGFR were only RAS wild-type or not. In our study, the expression of pAKT was associated with a higher response rate, but no statistically significant difference in PFS and OS was found $(\mathrm{HR}=1.004 ; 95 \% \mathrm{CI}(0.995 ; 1.013)$ and $\mathrm{HR}=1.006 ; 95 \% \mathrm{CI}$ (0.996; 1.016), respectively). In the study of Saglam et al (2007), an increasing in the pAKT expression has been described during colorectal cancer progression. We hypothesise that the overexpression of pEGFR induces better response rate for $R A S$ wild- type patients treated with anti-EGFR; however, this overexpression of pEGFR induces an overexpression of pAKT that leads to progression and annihilates anti-EGFR benefits and explains that no statistically significant difference in PFS was found. As already suggested, AKT may be an interesting target in colorectal cancers (De Roock et al, 2011; Jeong et al, 2014). Ongoing trials are currently testing an allosteric inhibitor of AKT, the MK-2206 (Agarwal et al, 2014; Jeong et al, 2014) in patients with mCRC. On the basis of our results, we hypothesise that associating anti-EGFR and anti-AKT therapies may be of interest in RAS wild-type patients.

In conclusion, these data suggest that the overexpression of pEGFR and pAKT may be response-predictive biomarkers for RAS wild-type patients treated with anti-EGFR, and, on the basis of our results, we hypothesise that the association of anti-EGFR and antiAKT therapies could be of interest.

\section{ACKNOWLEDGEMENTS}

This work has been supported by the translational research programme INCa 2009-1-RT-03 and the FP7 APODECIDE.

\section{CONFLICT OF INTEREST}

The authors declare no conflict of interest.

\section{REFERENCES}

Agarwal E, Chaudhuri A, Leiphrakpam PD, Haferbier KL, Brattain MG, Chowdhury S (2014) Akt inhibitor MK-2206 promotes anti-tumor activity and cell death by modulation of AIF and Ezrin in colorectal cancer. BMC Cancer 14: 1471-2407.

Altman DG, Royston P (2000) 'What do we mean by validating a prognostic model?'. Stat Med 19(4): 453-473.

Bokemeyer C, Van Cutsem E, Rougier P, Ciardiello F, Heeger S, Schlichting M, Celik I, Kohne CH (2012) Addition of cetuximab to chemotherapy as first-line treatment for KRAS wild-type metastatic colorectal cancer: pooled analysis of the CRYSTAL and OPUS randomised clinical trials. Eur J Cancer 48: 1466-1475.

Cejas P, Lopez-Gomez M, Aguayo C, Madero R, Moreno-Rubio J, de Castro Carpeño J, Belda-Iniesta C, Barriuso J, Moreno García V, Díaz E, Burgos E, Gonzalez-Barón M, Feliu J (2012) 'Analysis of the concordance in the EGFR pathway status between primary tumors and related metastases of colorectal cancer patients:implications for cancer therapy.. Curr Cancer Drug Targets 12(2): 124-131.

Chergui F, Chretien AS, Bouali S, Ramacci C, Rouyer M, Bastogne T, Genin P, Leroux A, Merlin JL (2009) Validation of a phosphoprotein array assay for characterization of human tyrosine kinase receptor downstream signaling in breast cancer. Clin Chem 55: 1327-1336.

Custodio A, Feliu J (2013) Prognostic and predictive biomarkers for epidermal growth factor receptor-targeted therapy in colorectal cancer: beyond KRAS mutations. Crit Rev Oncol Hematol 85: 45-81.

De Roock W, De Vriendt V, Normanno N, Ciardiello F, Tejpar S (2011) KRAS, BRAF, PIK3CA, and PTEN mutations: implications for targeted therapies in metastatic colorectal cancer. Lancet Oncol 12: 594-603.

De Roock W, Piessevaux H, De Schutter J, Janssens M, De Hertogh G, Personeni N, Biesmans B, Van Laethem JL, Peeters M, Humblet Y, Van Cutsem E, Tejpar S (2008) KRAS wild-type state predicts survival and is associated to early radiological response in metastatic colorectal cancer treated with cetuximab. Ann Oncol 19: 508-515.

Di Fiore F, Blanchard F, Charbonnier F, Le Pessot F, Lamy A, Galais MP, Bastit L, Killian A, Sesboue R, Tuech JJ, Queuniet AM, Paillot B, Sabourin JC, Michot F, Michel P, Frebourg T (2007) Clinical relevance of KRAS mutation detection in metastatic colorectal cancer treated by Cetuximab plus chemotherapy. Br J Cancer 96: 1166-1169.

Douillard JY, Oliner KS, Siena S, Tabernero J, Burkes R, Barugel M, Humblet Y, Bodoky G, Cunningham D, Jassem J, Rivera F, Kocakova I, 
Ruff P, Blasinska-Morawiec M, Smakal M, Canon JL, Rother M, Williams R, Rong A, Wiezorek J, Sidhu R, Patterson SD (2013) Panitumumab-FOLFOX4 treatment and RAS mutations in colorectal cancer. N Engl J Med 369: 1023-1034.

Harrell Jr FE, Lee KL, Mark DB (1996) Multivariable prognostic models: issues in developing models, evaluating assumptions and adequacy, and measuring and reducing errors. Stat Med 15: 361-387.

Iwamoto S, Hazama S, Kato T, Miyake Y, Fukunaga M, Matsuda C, Bando H, Sakamoto J, Oba K, Mishima H (2014) Multicenter phase II study of second-line cetuximab plus folinic acid/5-fluorouracil/irinotecan (FOLFIRI) in KRAS wild-type metastatic colorectal cancer: the FLIER study. Anticancer Res 34: 1967-1973.

Jemal A, Bray F, Center MM, Ferlay J, Ward E, Forman D (2011) Global cancer statistics. Ca 61: 69-90.

Jeong WJ, Cha PH, Choi KY (2014) Strategies to overcome resistance to epidermal growth factor receptor monoclonal antibody therapy in metastatic colorectal cancer. World J Gastroenterol 20: 9862-9871.

Khambata-Ford S, Garrett CR, Meropol NJ, Basik M, Harbison CT, Wu S, Wong TW, Huang X, Takimoto CH, Godwin AK, Tan BR, Krishnamurthi SS, Burris 3rd HA, Poplin EA, Hidalgo M, Baselga J, Clark EA, Mauro DJ (2007) Expression of epiregulin and amphiregulin and K-ras mutation status predict disease control in metastatic colorectal cancer patients treated with cetuximab. J Clin Oncol 25: 3230-3237.

Laurent-Puig P, Cayre A, Manceau G, Buc E, Bachet JB, Lecomte T, Rougier P, Lievre A, Landi B, Boige V, Ducreux M, Ychou M, Bibeau F, Bouche O, Reid J, Stone S, Penault-Llorca F (2009) Analysis of PTEN, BRAF, and EGFR status in determining benefit from cetuximab therapy in wild-type KRAS metastatic colon cancer. J Clin Oncol 27: 5924-5930.

Lievre A, Bachet JB, Boige V, Cayre A, Le Corre D, Buc E, Ychou M, Bouche O, Landi B, Louvet C, Andre T, Bibeau F, Diebold MD, Rougier P, Ducreux M, Tomasic G, Emile JF, Penault-Llorca F, Laurent-Puig P (2008) KRAS mutations as an independent prognostic factor in patients with advanced colorectal cancer treated with cetuximab. J Clin Oncol 26: 374-379.

Linardou H, Dahabreh IJ, Kanaloupiti D, Siannis F, Bafaloukos D, Kosmidis P, Papadimitriou CA, Murray S (2008) Assessment of somatic k-RAS mutations as a mechanism associated with resistance to EGFR-targeted agents: a systematic review and meta-analysis of studies in advanced non-small-cell lung cancer and metastatic colorectal cancer. Lancet Oncol 9: $962-972$.

Mirzoeva OK, Das D, Heiser LM, Bhattacharya S, Siwak D, Gendelman R, Bayani N, Wang NJ, Neve RM, Guan Y, Hu Z, Knight Z, Feiler HS, Gascard P, Parvin B, Spellman PT, Shokat KM, Wyrobek AJ, Bissell MJ, McCormick F, Kuo WL, Mills GB, Gray JW, Korn WM (2009) Basal subtype and MAPK/ERK kinase (MEK)-phosphoinositide 3-kinase feedback signaling determine susceptibility of breast cancer cells to MEK inhibition. Cancer Res 69: 565-572.

Newbold R (1984) Cancer: mutant ras proteins and cell transformation. Nature 310: 628-629.

Perkins G, Lievre A, Ramacci C, Meatchi T, de Reynies A, Emile JF, Boige V, Tomasic G, Bachet JB, Bibeau F, Bouche O, Penault-Llorca F, Merlin JL, Laurent-Puig P (2010) Additional value of EGFR downstream signaling phosphoprotein expression to KRAS status for response to anti-EGFR antibodies in colorectal cancer. Int J Cancer 127: 1321-1331.

Razis E, Pentheroudakis G, Rigakos G, Bobos M, Kouvatseas G, Tzaida O, Makatsoris T, Papakostas P, Bai M, Goussia A, Samantas E, Papamichael D, Romanidou O, Efstratiou I, Tsolaki E, Psyrri A, De Roock W, Bafaloukos D, Klouvas G, Tejpar S, Kalogeras KT, Pectasides D, Fountzilas G (2014) EGFR gene gain and PTEN protein expression are favorable prognostic factors in patients with KRAS wild-type metastatic colorectal cancer treated with cetuximab. J Cancer Res Clin Oncol 140: 737-748.

Saglam O, Garrett CR, Boulware D, Sayegh Z, Shibata D, Malafa M, Yeatman T, Cheng JQ, Sebti S, Coppola D (2007) Activation of the serine/ threonine protein kinase AKT during the progression of colorectal neoplasia. Clin Colorectal Cancer 6: 652-656.

Sauerbrei W, Schumacher M (1992) A bootstrap resampling procedure for model building: application to the Cox regression model. Stat Med 11: 2093-2109.

Scartozzi M, Giampieri R, Maccaroni E, Mandolesi A, Biagetti S, Alfonsi S, Giustini L, Loretelli C, Faloppi L, Bittoni A, Bianconi M, Del Prete M, Bearzi I, Cascinu S (2012) Phosphorylated AKT and MAPK expression in primary tumours and in corresponding metastases and clinical outcome in colorectal cancer patients receiving irinotecan-cetuximab. J Transl Med 10: 1479-5876.

Sorich MJ, Wiese MD, Rowland A, Kichenadasse G, McKinnon RA, Karapetis CS (2014) Extended RAS mutations and anti-EGFR monoclonal antibody survival benefit in metastatic colorectal cancer: a meta-analysis of randomized controlled trials. Ann Oncol 2014.

Tougeron D, Lecomte T, Pages JC, Villalva C, Collin C, Ferru A, Tourani JM, Silvain C, Levillain P, Karayan-Tapon L (2013) Effect of low-frequency KRAS mutations on the response to anti-EGFR therapy in metastatic colorectal cancer. Ann Oncol 24: 1267-1273.

This work is published under the standard license to publish agreement. After 12 months the work will become freely available and the license terms will switch to a Creative Commons AttributionNonCommercial-Share Alike 4.0 Unported License 